\title{
El monopolio del poder en la Extremadura Contemporánea
}

\author{
María Jesús Merinero Martín y Fernando Sánchez Marroyo*
}

\section{INTRODUCCIÓN}

Perseguimos con esta comunicación un doble objetivo. Por un lado se trata de dar noticia de un proyecto a largo plazo, en parte culminado, en parte en realización, que constituye una de las líneas de investigación que desarrollamos en el Área de Historia Contemporánea del Departamento de Historia de la Universidad de Extremadura. Por otro, se pretende ofrecer, junto a información del método de trabajo, algunos resultados parciales ${ }^{1}$ sobre uno de los aspectos en que se concreta aquel proyecto. Estudio de carácter global, comprende diferentes planos, dentro de un objetivo general que es el análisis de las élites de notables monopolizadoras de las instancias de poder, y con ello de decisión, en la Extremadura Contemporánea. Desde este punto de vista se consideran no sólo a los grupos políticos, detentadores de la representación popular, sino también, en estrecha relación, por la existencia de unas sólidas bases patrimoniales, a las oligarquías locales y regionales, su caracterización, procedencia social, el origen de sus fortunas y las formas de gestión patrimonial. El ámbito temporal se inicia con el establecimiento del régimen representativo, en los inicios del siglo xIX, y culmina en el

* Universidad de Extremadura.

- Parciales en tanto lo consideramos como una parte del proyecto global de estudio de la contemporaneidad; sin embargo, entendidos individualmente, como análisis sectoriales, tienen contenido pleno como obras cerradas y culminadas en sí mismas. 
momento que se entra en un régimen autoritario, al finalizar la Segunda República.

Análisis, pues, montado en el doble plano de lo político y lo socioeconómico. En el ámbito estrictamente político distinguimos diferentes niveles de representación, todos los cuales son recogidos en el trabajo:

Representación nacional: Diputados a Cortes y senadores (y en algunos casos ministros). Caracterización, lo más exhaustiva posible, de todos los diputados extremeños que resultaron elegidos en las 54 consultas generales desde 1810 hasta 1936, así como de los senadores que, de acuerdo con los distintos modelos constitucionales, representaron a las dos provincias en el mismo período ${ }^{2}$.

Representación provincial: Diputados Provinciales y presidentes de la Diputación (y también, aun cuando no son cargos representativos y por lo que se apunta más adelante, Gobernadores civiles).

Representación local: (Ayuntamientos), concejales y alcaldes.

En el ámbito socioeconómico: la oligarquía agraria, fuerza social hegemónica, detentadora de los niveles de renta y decisión (social, política y económica) fundamentales. Sus relaciones familiares, su entidad patrimonial, las formas de gestión empresarial, las implicaciones políticas, etc.

\section{EL BANCO DE DATOS}

Como soporte de la investigación y medio de procesamiento de los datos se utiliza la herramienta informática ${ }^{3}$. Ello ha permitido poner a

${ }^{2}$ Por las características que tuvo siempre la representación senatorial, los miembros de la Cámara Alta, bien en su totalidad (etapa isabelina), bien en un buen número (por derecho propio y nombrados por la Corona, en la Restauración), accedían al cargo por caminos distintos a los estrictamente electivos lo que les privaba de significación territorial concreta. Sin embargo, en el Senado se integraron siempre destacados miembros de la oligarquía nacional, especialmente aristócratas, con fuerte presencia patrimonial en Extremadura. De hecho, algunos de ellos, que iniciaron su vida pública muy jóvenes, tuvieron que ser diputados el tiempo mínimo imprescindible, exigido por imperativo legal, ante la imposibilidad de sentarse en aquella Cámara antes de los 30 ó 35 años. Fue el caso, entre otros intereses en Extremadura, de Joaquín Fernández de Córdova y Osma, VIII duque de Arión, de Felipe Faicó y Ossorio, VIII duque de Montellano, etc.

${ }^{3}$ Concretado en un ordenador personal Macintosh. La Base de Datos se ha construido 
punto un gran Banco de Datos, en el que se recoge una caracterización completa de cada uno de los personajes que interesan, en el caso que se va a tratar aquí los alrededor de mil nombres de los diputados y senadores que representaron ${ }^{4}$ a Extremadura entre 1810 y 1936 . Además se incluyen también a diputados a Cortes que si bien nunca alcanzaron el acta por un distrito extremeño, formaban parte de lo más destacado de su oligarquía agraria ${ }^{5}$.

Se incorpora un modelo de ficha de trabajo, multivalente y fácilmente adaptable a cualquier cambio, utilizada para el vaciado de los datos. Es de advertir que está diseñada para recoger todo el personal político regional, desde los niveles mínimos (concejales y alcaldes) hasta los más altos (diputados a Cortes y senadores) pasando por los cargos provinciales (Diputación Provincial, gobernadores Civiles ${ }^{6}$ ). La entrada de estos

a partir del programa Microsoft File, elemental y muy manejable, que permite continuas adaptaciones a la marcha del trabajo y en última instancia transportar la información contenida, llegado el caso, a otros programas más potentes, como es el caso del Filemaker II, que prácticamente requiere, para dar todo su rendimiento, un disco duro. La información contenida en nuestro Banco de Datos se encuentra a disposición de cualquier investigador interesado en el tema.

${ }^{4} \mathrm{Tal}$ como se ha apuntado, la representatividad política, que no la social y económica, de los senadores, así como su territorialidad, era limitada; sin embargo, y por ello mismo, se recogen en el Banco a notorios personajes de protagonismo nacional, que representativos o no tenían en Extremadura cuantiosos intereses: conde de Fuenclara, duque de Alba duque de Medinaceli, marqués de Miraflores, Jerónimo del Moral, conde de la Puebla del Maestre, duque de la Roca, conde de Santa Coloma, conde de Superunda, marqués de Távara, marqués de la Torrecilla, barón de Velasco, etc. La literatura «doliente» extremeña, de raíz regeneracionista, dedicó siempre a estos personajes los juicios más severos, acusándolos implícitamente de ser los grandes responsables de la postración regional. Una curiosa visión en este sentido, donde se hace referencia de forma genérica a uno de estos personajes, convertido en verdadero símbolo de la degeneración social, que repartía su vida inútil entre "el Senado, como sport, y el Casino de Madrid, como entretenimiento", puede verse en CASTLLLO, M., Extremadura, México, Casa de Extremadura, 1950.

${ }^{5}$ Son los casos, por citar a algunos bien notorios, de algunos miembros de la familia Udaeta: Santiago Udaeta y Villachica, diputado conservador por el distrito salmantino de Peñaranda de Bracamonte en 1903, 1905 y 1907 y destacado terrateniente en la provincia de Cáceres; Tomás de Beruete y Udaeta, liberal, Diputado por Talavera de la Reina en 1903, 1905, 1910, 1914, también gran propietario rústico en la Alta Extremadura; Gaspar Muñoz Jarava, senador por Ciudad Real y miembro de uno de los más rancios, tradicionales y acaudalados linajes cacereños, aunque afincado en la provincia manchega desde el XIX; etc. Esto, no se olvide, aumenta la virtualidad extraregional de nuestro Banco al laborar en pro de la necesaria integración de esfuerzos locales en un gran proyecto colectivo, que permitiría, sin grandes problemas técnicos dadas las virtualidades prácticas de la herramienta informática y con escaso coste humano por el hecho de trabajar con un equipo numeroso, obtener una definitiva visión de conjunto, con las múltiples ventajas derivadas de la globalidad, sobre el ejercicio del poder en la España Contemporánea. Es un reto y, al mismo tiempo, una invitación que lanzamos desde estas páginas.

${ }^{6}$ Por las características que concurren en este cargo, su importancia trasciende el 
datos locales constituye una segunda fase del trabajo, en la actualidad en sus inicios.

Cada uno de los campos que constituyen la Base de Datos permite una rápida ordenación del material, así como la localización de las variables concretas que interesen en cualquier momento, desde lo más elemental, tanto los aspectos espaciales (por ejemplo, diputados por un distrito a lo largo del tiempo), como los temporales (diputados extremeños en una legislatura determinada), pasando por la filiación política, hasta aquellos otros factores que conllevan una información cualitativa más específica (individuos con unos intereses económicos determinados).

Por otra parte, este Banco, al estar montado en un ordenador personal de amplia capacidad, une a todas las potencialidades características del trabajo informático, la que se deriva de la independencia que permite, lo que acrecienta su virtualidad práctica.

Es preciso tener en cuenta además que, si se quiere obtener una mayor información sobre los aspectos más estrictamente socioeconómicos (por ejemplo, la gestión empresarial, la caracterización minuciosa de los patrimonios, etc.), el solo manejo de este Banco de Datos resulta insuficiente. Debe, por tanto, ser complementado con otros, de estructura similar, pero con contenido diferente, que se encuentran en avanzado estado de elaboración, sobre los que no se trata en este trabajo. De esta forma se consigue profundizar en la caracterización de la oligarquía dominante social y politicamente en Extremadura y, en última instancia, se avanza en el análisis de los mecanismos de perpetuación del poder. Idea de futuro es la de integrar toda esta información en una única Base de Datos, lo que permitiría trabajar con altos niveles de exhaustividad. De esta manera, el historiador podrá dedicar todo su tiempo al análisis, libre

marco estrictamente regional, siendo de utilidad la información contenida en el Banco a ámbitos espaciales más amplios. Por ello se recoge a personajes que si bien ocuparon este cargo público fuera de Extremadura, tenían en ella grandes intereses económicos. Formaban parte en definitiva de la oligarquía agraria regional. Es el caso de Felipe Padierna de Villapadierna, en 1868 gobernador civil de Zamora, donde llevó a cabo una importante labor benéfica que merecería el reconocimiento del gobierno. En el último cuarto de siglo, ya ennoblecido con el título de conde de Villapadierna, se convirtió en uno de los mayores propietarios rústicos de Extremadura, como beneficiario, en Badajoz, de la quiebra de la Casa de Osuna. Efectivamente, en 1873 había adquirido la dehesa de Cijara, en Herrera del Duque, del más rancio y tradicional patrimonio de la Casa, que con sus 10.430 Has. era una de las grandes fincas de Extremadura. En sentido contrario aparecen en el Banco gobernadores civiles de otras provincias, que fueron Diputados por distritos extremeños, como fue el caso entre otros de Jesús Lopo Gómez, pacense, primera autoridad civil de Jaén en 1910. 
de la pesada carga de la manipulación artesanal de los datos, que tantas horas de trabajo ha venido requiriendo tradicionalmente.

\section{ESTADO DE LA CUESTIÓN}

Aunque se trata de una investigación de ámbito regional, no todo el espacio extremeño ha sido objeto hasta ahora de la misma atención y de ello se deriva un muy distinto grado de conocimiento de sus diversas realidades espaciales. La provincia de Cáceres ha sido estudiada parcialmente, la Restauración de forma exhaustiva, por los dos autores de este trabajo, tanto en lo que se refiere a las élites políticas ${ }^{7}$, como económicas ${ }^{8}$. De esta manera disponemos de unos sólidos puntos de partida, basamento de todo el trabajo. Otras etapas históricas son más desconocidas, aunque de algunas de ellas se han realizado notables avances ${ }^{9}$.

La provincia de Badajoz conoce sólo estudios parciales, unos en elaboración y otros ya publicados ${ }^{10}$. Sobre ella se ha centrado el mayor esfuerzo de investigación, que ha permitido alcanzar hoy un aceptable grado de conocimiento.

\section{LAS ÉLITES POLÍTICAS EN EXTREMADURA}

De una forma más concreta en este trabajo se realiza una aproximación a los rasgos más característicos de las élites parlamentarias (di-

7 Merinero Martín, M. ${ }^{a}$ J., Comportamiento político de Cáceres (1890-1931), Cáceres, Institución Cultural El Brocense, 1981.

8 SÁnchez Marroyo, F., El campo y el campesinado cacereño durante la Restauración. Formas de propiedad y explotación (1870-1920), Tesis doctoral inédita, Universidad de Extremadura, 1982.

9 Las elecciones de la Segunda República han sido estudiadas por AYALA VICENTE, F., La vida política en Cáceres durante la I/ República, Memoria de Licenciatura inédita, Universidad de Extremadura, 1989. La primera mitad del siglo xIX, sin embargo, no ha merecido aún en el plano de los estudios políticos ninguna atención.

${ }_{10}$ Un estudio comarcal, esbozo de análisis global, puede verse en SÁnchez MARROYO, F., "La génesis de un grupo por poder local: la oligarquía agraria de La Serena a mediados del XIX", en Actas del I Encuentro de Investigación Comarcal (Los Montes, La Serena y Vegas Altas), Villanueva de la Serena, ADECO, 1989, págs. 131-151. 
putados a Cortes y senadores) de Extremadura en el primer tercio del $\mathrm{XX}$, aunque para enmarcar significativamente el análisis se retroceda, a modo de introducción, al siglo Xix (Etapa Isabelina, Sexenio democrático y Restauración en sentido estricto).

La evolución de los rasgos socioprofesionales ${ }^{11}$ del personal político extremeño desde la primera mitad del siglo XIX va a estar en relación con el grado de apertura del sistema, su mayor o menor sensibilidad a la hora de captar la voluntad del electorado, y con el propio grado de movilización de éste. Como rasgo general, desde el punto de vista de la extracción social de los parlamentarios, en los primeros momentos, en los que domina el sistema censitario, hay una estrecha conexión entre oligarquía local (de estructura básicamente agropecuaria) y cargo público representativo. Luego, con el paso del tiempo, la maduración del régimen y como consecuencia de la misma evolución que conoce la sociedad española se produce una mayor profesionalización y diversificación (que se hará definitiva en las experiencias republicanas), aunque los señores de la tierra seguirán estando presentes.

En los primeros momentos del régimen representativo hubo que improvisar una clase política que, obviamente, se nutrió de las tradicionales oligarquías locales del Antiguo Régimen. En ellas desempeñaban un papel clave los grandes propietarios rústicos (o ganaderos, en su caso, por la importancia que tenía la riqueza pecuaria en Extremadura y el escaso dinamismo, hasta que se inició la Reforma Agraria Liberal, de la propiedad rústica), que monopolizaban la representación. El estudio de las circunstancias reales de cada uno de los diputados, al margen de su profesión concreta, resulta en estos casos fundamental.

Como elemento distintivo, presente de manera constante en toda la Historia Contemporánea extremeña hay que resaltar, por encima de cualquier otro rasgo, la idea de "continuidad", la permanencia, con carácter intemporal, de unos determinados grupos familiares al frente de los diferentes niveles que constituyen las instancias de decisión. Continuidad

11 Lo de clasificación socioprofesionaí debe ser entendido en sentido amplio y, por ello mismo, tomado con reservas al tratarse de un ambiente profundamente ruralizado y mayoritariamente campesino, con reducida presencia del fenómeno urbano y de las actividades a ello inherentes. Los más importantes núcleos de población admitirian ser incluidos, a lo más, dentro de la categoría que los geógrafos han caracterizado como «agro-villas». Por otro lado, buena parte de los grandes propietarios rústicos, y sobre todo los miembros de la nobleza, eran abogados; pero este dato resulta irrelevante, porque resulta evidente que no procedían de aquí sus cuantiosas rentas. 
que tiene una base patrimonial y una notable proyección en el plano representativo, manifestado en un triple nivel:

- Continuidad «filial», padres e hijos se suceden o alternan durante décadas en el monopolio de la representación. Es el caso de los diputados a Cortes: Pablo Montesino (diputado por Extremadura en 1821 y por Badajoz en 1843), Cipriano S. Montesino (diputado por Cáceres en 1854, por Brozas en 1858, por Cáceres en 1869 y por Alcántara en 1871) y Luis Montesino y Fernández-Espartero, Marqués de Morella, (diputado por Alcántara en 1898, 1901, 1903 y 1905), padre, hijo y nieto; Joaquín Rodríguez Leal (diputado por Badajoz en 1836, por Mérida en 1846 y por Cáceres en 1841, 1854) y Ramón Rodríguez Leal (diputado por Plasencia en 1858, 1869), padre e hijo y lo mismo ocurrió con Antonio González (diputado por Badajoz en 1834, 1836, 1837, 1843 y 1845) y Ulpiano González (diputado por Llerena en 1881, 1886, 1893); Vicente Silva (diputado por Cáceres en 1837 y por Plasencia en 1846 y 1863) y Julián Silva y García-Monje (diputado por Plasencia en 1865); Modesto Durán Corchero (diputado por Hoyos en 1871 y 1872) y Rafael Durán Martín (diputado por Hoyos en 1901, 1903 y 1905); Manuel Molano (diputado por Badajoz en 1846, 1850, 1851) y Leopoldo Molano (diputado por Badajoz en 1864, 1867, 1881 y 1884), etcétera.

- Continuidad «personal». Una misma persona acapara la representación durante largas etapas. Un caso significativo durante la etapa isabelina es el de Santiago Fernández Negrete ${ }^{12}$, diputado «moderado» perpetuo por Llerena entre 1843 y 1864 , salvo durante la breve experiencia progresista de 1854-56. Otros casos semejantes fueron los de Joaquín González Fiori, diputado por Hoyos desde 1876 hasta 1899, con el breve paréntesis de 1884; Laureano García-Camisón y Domínguez, diputado ininterrumpido por Coria entre 1891 y 1907, etcétera.

- Continuidad «familiar», diferentes miembros de un mismo clan familiar se suceden durante generaciones en el control de diversas instancias de poder público y representativo, desde las alcaldías a las Cortes, pasando por las Diputaciones Provinciales. En este sentido se puede hablar de la existencia de verdaderas dinastías de políticos, que "heredan" los cargos representativos. En la provincia de Badajoz son de destacar los casos de la familia Pacheco, de Mérida, cuyos miembros se alternaron durante generaciones en la representación política pacense,

${ }_{12}$ Aunque de origen asturiano, Santiago Fernández Negrete, varias veces ministro entre 1851 y 1864, fue un hombre profundamente ligado a Extremadura, donde residió habitualmente, ejerció cargos públicos, se casó y representó políticamente durante décadas. 
desde las primeras etapas del Régimen liberal hasta la Dictadura de Primo de Rivera ${ }^{13}$; las familias Albarrán, Molano, Lopo, de Badajoz, etc. En Cáceres sobresalieron en este sentido los Pérez Aloe, de Trujillo, que mostraron una notable capacidad de supervivencia política, adaptándose a los diferentes cambios de situación que se dieron en el país ${ }^{14}$.

El personal político que se considera ahora especialmente, diputados a Cortes, fue seleccionado a través de las diferentes consultas electorales que se produjeron entre 1810 y 1936 , entre las cuales mediaron abismales diferencias, derivadas tanto de la propia concepción de la representación, como en la misma estructura de la ley electoral, factores decisivos, cada uno a su manera, a la hora de convertir la voluntad del electorado en escaños:

- Dos consultas en la primera etapa constitucional (Guerra de la Independencia).

- Dos consultas en la segunda etapa constitucional (Trienio Constitucional).

- Veintiuna en el Reinado de Isabel II.

- Cinco en el Sexenio Democrático.

- Veintiuna en la Restauración.

- Tres en la II República.

Por ello se pueden distinguir diversos momentos, con sus características propias, en lo que se refiere a los rasgos sociopolíticos de los representantes extremeños. En este sentido fue notable la incidencia del Sexenio y de la II República en el reclutamiento de los grupos que tradicionalmente monopolizaban la representación política regional.

\section{Etapa isabelina}

1. Ausencia casi total en el Congreso de Diputados de personajes ajenos al ámbito provincial. Excepcionalmente aparecen con patrimonios

${ }^{13}$ Inició la dinastía Antonio Clemente Pacheco; le sucedió su sobrino Alonso Pacheco García-Blanes y a éste sus hijos Carlos y Antonio Pacheco y Lerdo de Tejada. Los primeros se movieron en el ámbito de la política local, empleando sus esfuerzos, sobre todo, en amasar una considerable fortuna de origen comercial, pero con firmes basamentos agrarios. Los últimos, especialmente Antonio, se dedicaron más intensamente a la política nacional, controlando durante décadas el distrito de Mérida.

${ }_{14}$ Que no interrumpió la Dictadura de Primo de Rivera. Juan Antonio Pérez Aloe era en 1926 Presidente de la Unión Patriótica del partido de Trujillo. 
recién adquiridos en la zona, aprovechando las grandes transferencias de propiedades que la Reforma Agraria Liberal determinó. Son los casos de Lorenzo Santa Cruz y Mújica (diputado por Castuera en 1863, 1864 y 1865), Antonio Angel Moreno (diputado por Brozas en 1863), José Luis Retortillo (diputado por Navalmoral de la Mata en 1863), etc., todos de Madrid y bien grandes propietarios ellos mismos, o parientes de terratenientes, en la comarca. Esta excepcionalidad se rompe en lo que respecta al Senado. Aquí se da una abultada presencia de notables nacionales, con muy ligeros nexos regionales.

2. Dominio, claramente mayoritario, por razones evidentes, de los grandes propietarios rústicos, con la inclusión, episódica, de algún personaje oriundo notable en Madrid, bien en el campo político (Juan Bravo Murillo), bien en el cultural (José Moreno Nieto). En general, resulta muy díficil encontrar a parlamentarios que no pertenezcan a la oligarquía agraria. Incluso algunos de estos, que hicieron fortuna en la capital del Reino por su dedicación a actividades liberales, terminaron adquiriendo con el tiempo un considerable patrimonio rústico en Extremadura ${ }^{15}$. Lo cual no deja de ser una clara muestra de un firme y lúcido criterio de racionalidad económica, dado que la riqueza productiva básica de la zona radicaba en el campo y, por otra parte, a mediados del XIX la renta de la tierra estaba experimentando un gran incremento en ambas provincias ${ }^{16}$.

3. Estrecha relación con las oligarquías locales del Antiguo Régimen, buena parte de cuyos miembros, aunque no titulados, pertenecian a la nobleza (hidalgos, caballeros). La ausencia de ese elemento distintivo (título) hace que se terminen confundiendo, en la nueva sociedad liberal, con los que constituían el difuso grupo que, convencionalmente, llamamos burguesía. Apellidos como Vera, Laguna, Fernández-Golfín, Claros, Villanueva, Donoso, Barrantes, Cabeza de Vaca (o Baca), Andrés de la Cámara, etc., en Badajoz, son clara muestra de lo que decimos.

4. Presencia de la nobleza de procedencia regional (Condes de Casa Ayala, conde de Torre Arce, marqués de la Encomienda, conde del Alamo, marqués de Riocavado, márques de Casa Mena, marqués de la

15 El caso más destacado fue el del propio Juan Bravo Murillo, que compró a mediados de siglo dos grandes dehesas, una de ellas, en Logrosán, rondaba las $10.000 \mathrm{Has}$, de tal forma que se convirtió en uno de los mayores terratenientes de la provincia de Cáceres.

${ }^{16}$ Hemos documentado este ascenso, ininterrumpido, del precio de los arrendamientos rústicos en Extremadura en el segundo tercio del XIX en SÁNCHEZ MARROYO, F., «Notas sobre los orígenes de la oligarquía agraria en Extremadura a mediados del siglo XIX", comunicación presentada al Simposio Internacional de Historia Rural, Santiago de Compostela, 1988, (En prensa). 
Conquista, marqués de Castro-Serna, conde de Torreorgaz). Otros, de rancias familias locales, serían ennoblecidos con el paso del tiempo por la propia monarquía liberal, bien por Isabel: marqués de Valdegamas, marqués de Valdeterrazo; bien por su hijo, conde de Campos de Orellana.

El «Sexenio Democrático», introdujo algunas innovaciones, tanto más intensas cuanto más avanzado y rupturista con lo que había sido tradicionalmente el ejercicio del poder en España se hacía el sistema.

1. Relativa continuidad en los diputados, con reaparición de progresistas condenados al ostracismo en las etapas de predominio moderado (Carlos Godínez de Paz, Juan Andrés Bueno, etc.). Sus discrepancias con el moderantismo eran más de forma y talante que de fondo, pues buena parte de ellos pertenecían al colectivo de destacados terratenientes ${ }^{17}$.

2. Desaparición de las más notables figuras del conservadurismo isabelino, en unos casos por extinción biológica y en otras por retirada estratégica. De esta manera volverían a reaparecer en cuanto las circunstancias políticas cambiasen.

3. Aparición de más profesionales, pero ligados estrechamente a los intereses de los grandes propietarios. Fue el caso de Antonio Cortijo Valdés, de Villanueva de la Serena, abogado del marqués de Perales y otros aristócratas y grandes propietarios madrileños en el pleito de la Real Dehesa de La Serena.

4. Continuidad de los grandes intereses agrarios: conde de Villanueva de Perales y futuro marqués de Perales, el mayor propietario rústico de Badajoz; marqués de Camarena, Modesto Durán Corchero, Santiago de Angulo, etc.

5. Sólo durante la Primera República, por la inhibición de las fuerzas más tradicionales, se produjo una momentánea renovación total del personal político, salvando la presencia anecdótica de algún gran terrateniente aristócrata ${ }^{18}$.

${ }^{17}$ Carlos Godínez de Paz, abogado cacereño, había terminado convirtiéndose, al liegar el Sexenio, si no por la calidad de las tierras, sí por el número de hectáreas poseídas, en uno de los primeros terratenientes de la provincia de Cáceres.

${ }^{18}$ Fue el caso de Enrique Pérez de Guzmán el Bueno y Gallego, marqués de Santa Marta por su matrimonio con Concepción Gordón y Golfín, la mayor propietaria rústica de la provincia de Cáceres en aquellos momentos. Su hijo Alfonso, que heredó el título materno, seguiría la vocación política paterna, pero con una orientación radicalmente diferente. Fue diputado conservador por Cáceres en 1896, 1903, 1907 y senador por derecho propio desde 1910. 
«La Restauración» consolidó los modelos de comportamiento caracteristicos de la etapa isabelina en Extremadura, perfeccionando los sistemas de control. Lo importante ahora, incluso con sufragio universal, no es tanto el proceso de elección en sí, sino el mecanismo social que posibilita la selección de los candidatos. Con respecto a la etapa política inmediata anterior, Primera República, y en general con relación al Sexenio Democrático, dos son los rasgos diferenciales:

1. Vuelta de algunas de las grandes figuras supervivientes del pasado (Pedro Nicomedes Campos de Orellana, Cipriano Piñero, Manuel Pérez-Aloe y Elías, Conde de la Encina), o sus herederos (Luis Villanueva y Cañedo, Manuel M. ${ }^{a}$ y Arcadio Albarrán y García Márquez, Juan de Morales Tohovar, hijos de los notables prohombres del moderantismo).

2. Continuidad de aquellos nombres ligados a los grandes intereses agrarios, que habían monopolizado la representación en la época isabelina y no habian desaparecido en las primeras fases del Sexenio: conde de Villanueva de Perales, marqués de la Conquista, Jacinto Balmaseda, y aparición masiva de otros nuevos, aristócratas (marqués de la Romana ${ }^{19}$; marqués de la Mina ${ }^{20}$; Agustín Díaz-Agero y Gutiérrez, conde de Malladas ${ }^{21}$ ) o no (Fernando Montero de Espinosa, Laureano GarcíaCamisón y Domínguez, Juan Muguiro Cerrajería, Basilio Gutiérrez Cedrún, Cipriano Higuero Ávila, etc).

Hechas estas consideraciones entramos en el estudio más en detalle de las élites políticas del primer tercio del siglo XX. El sistema político de la Restauración consiguió su prolongada continuidad gracias a la escrupulosa selección de los representantes bipartidistas y alternantes en el Congreso para lo que tuvo que elaborar, a partir de las experiencias anteriores, un engranaje electoral, tan corrupto, desde el punto de vista

19 Pedro Caro Szechenyi, VI marqués de la Romana, diputado conservador por el distrito de Navalmoral de la Mata en 1903, 1907 y 1919, poseía en esta comarca ingentes propiedades rústicas, adquiridas a fines del siglo XIX a otros miembros de la nobleza como el duque de Frías y el marqués de Salamanca.

${ }^{20}$ Manuel Felipe María Falcó y Ossorio, marqués de la Mina, era el segundo hijo, y el heredero del título, de la III duquesa de Fernán Núñez, dueña del más importante patrimonio territorial de Extremadura durante la Restauración. Inició su carrera política, como diputado a Cortes por Cáceres, nada más alcanzar los 25 años y, al llegar a los 40 , pasó a ser senador por derecho propio.

${ }^{21}$ Este aristócrata se dedicó a la vida política, diputado por Coria en 1879 , antes de alcanzar el título nobiliario, cuyo nombre proviene precisamente del de la finca, antigua encomienda de la Orden de Alcántara, sobre la que se montó el notable patrimonio territorial de la familia en Extremadura. 
del auténtico juego representativo, como eficaz para la sociedad que pretendía gobernar.

Las élites políticas extremeñas entre 1902 y 1923, reinado constitucional de Alfonso XIII, constituyen la parte proporcional de las élites socio-económicas regionales que permite la representación política. La desmovilización política, la dependencia económica de la mayoría de los electores, la desideologización de los partidos, y la endogamia familiar en la formación del nuevo grupo de poder, son pilares esenciales de los que se aprovecha el Gobierno para poder llevar a cabo sus proyectos de perpetuación de un orden social determinado.

Podría decirse que la estructura socio-económica de la región, eminentemente agrícola, hacía depender a los diputados de los votos del campo. El campesino, generalmente analfabeto y pobre, no entendía bien los términos políticos, y acostumbrado a desenvolverse en un sistema contractual, vigente en todas las actividades de su vida, fácilmente concedía su voto a quien le ofreciera algo a cambio, ya fueran grandes promesas o mínimos favores. Si la desideologización en gran parte de los electores era consecuencia lógica de su situación económica y cultural, no lo era menor, aunque por motivos bien dispares, la de los representantes políticos. $Y$ ésta era alentada con la fabricación del «encasillado", de tal forma que personas que habian iniciado su carrera política en una formación determinada podían continuarla en otra o beneficiase del apoyo de intereses formalmente antagónicos.

Es el caso del representante por Navalmoral, el abogado José Rosado Gil, que no tiene ningún escrúpulo en representar al partido liberal demócrata a partir de 1905 y conseguir su escaño, durante siete legislaturas, con el apoyo del núcleo más conservador del distrito, las fuerzas del marqués de la Romana y del marqués de Mirabel. Y, además, todo ello no impide que en su oportunismo político se presente como republicano radical por Cáceres en 1931. Su fracaso en esta ocasión no le desanimó y agotada la experiencia radical, logró en 1936, con el apoyo socialista $^{22}$, un escaño como centrista por la circunscripción de Badajoz. Las razones de esta versatilidad son evidentes, y las conocemos concretamente en el caso de otro liberal-demócrata, Rafael Durán Martín ${ }^{23}$,

${ }^{22}$ De acuerdo con el testimonio personal del principal responsable de la operación de trasvase de votos. Cfr. VIDARTE, J. S., Todos fuimos culpables. Testimonio de un socialista español, México, Fondo de Cultura Económica, 1973, págs. 36 y ss.

${ }^{23}$ Además de diputado a Cortes, Rafael Durán Martín, que heredó de su padre la preeminencia politica, fue gobernador civil de varias importantes provincias: Valencia y Sevilla. 
representante de esta tendencia en Hoyos en tres legislaturas, quien, en 1907 , se pasa al partido conservador cuya jefatura ostenta su suegro, Miguel Muñoz Mayoralgo.

De otro lado, gran parte de las clases medias y altas, también dependían de la agricultura. Como en las etapas anteriores, son numerosos los diputados identificados que viven de sus rentas agrarias o son grandes propietarios, sin ser nobles terratenientes. $Y$ es que, el asceso de la nueva clase de notables, la nueva burguesía agraria, fenómeno característico del siglo XIX, que había adquirido gran parte de las tierras puestas en el mercado por la Reforma Agraria Liberal, permitió su integración en el grupo de propietarios nobles, debilitando a este grupo como clase social única. A la vez que el reparto de títulos de nobleza entre hombres de negocios, expediente ya iniciado en la etapa isabelina y continuado en la primera fase de la Restauración, para recompensar lealtades políticas, ayudó a debilitar el sentimiento antiaristocrático entre la burguesía.

Son los casos del conde de los Moriles, Juan Vitórica Casuso, diputado a Cortes por Cáceres desde 1918, cuyo título le fue concedido en julio de 1921, y a quien se le otorgó la Grandeza de España en febrero de 1924; de Manuel Pidal y Bernaldo de Quirós, diputado a Cortes perpetuo por Almendralejo desde 1907 a 1920, que recibió en 1914 el título de marqués de Valderrey; de Julián de Olivares Ballivián, diputado por Alcántara en 1914, desde 1906 conde de Artaza y de Juan Alcalá-Galiano y Osma, diputado por Hoyos en 1920 y 1923 y desde 1915 conde de Romilla.

La endogamia familiar es importante para el ascenso y, a veces, el mantenimiento de este grupo en el poder. Lo tenemos representado por el diputado por Trujillo, Manuel Pérez Aloe, abogado y gran propietario, quien se ve incluido entre la nobleza al adquirir el título de conde de la Encina por matrimonio con M. ${ }^{a}$ Carmen Castillo Orellana.

Otro colectivo socio-estructural es el grupo de los funcionarios civiles (principalmente abogados, pero también médicos), parte importante de las clases medias, sobre todo en las capitales de provincias agrarias, que si no poseen intereses económicos específicos, se ven forzados a depender del padrinazgo del Gobierno y optarán por pertenecer a un partido de los que estén en el poder, para acomodar su situación ideológica a su aptitud política. Los abogados Ilegaron a dominar la vida política española, representando así una parte de la burguesía ilustrada y económica de los centros de decisión. En la Extremadura isabelina surgió una de las figuras más representativas de todas, la de Bravo Murillo. 
Durante la etapa que ahora interesa, el «clan» de los Muñoz Chaves ${ }^{24}$ sería el prototipo en Cáceres. Los Chaves llegaron a tender una red muy amplia de personas relacionadas entre sí únicamente por la protección de su política; a ella se debían no sólo los cargos ejercidos por la propia familia, sino el mantenimiento de candidatos conservadores, como el gran propietario Antonio Garay Vitórica, diputado por el distrito de Alcántara durante cinco elecciones desde 1916 a 1923. Dentro de esta red, la relación es bien diferente; unos son familiares directos: Joaquín y su hermano Juan Muñoz Chaves y sus respectivos hijos, Juan Muñoz Casillas y Juan Muñoz Fernández de Soria; otros son meros colaboradores y "clientes".

Joaquín representará a Alcántara en 1893, y llegará a ser senador; recordemos que la representación en el Senado comporta caracteres económicos y políticos satisfactorios, y que, en ocasiones, estos cargos eran una recompensa a los méritos políticos. Juan Muñoz Chaves conseguirá representar a Cáceres en 1905, y a Hoyos en 1907; además fue Senador por Granada en 1910 y por Cáceres en 1914. Su hijo, Juan Muñoz Casillas, que ya había sido nombrado gobernador interino en 1910, será representante de Coria en 1923; su sobrino, hijo de Joaquín, Juan Muñoz y Fernández de Soria, que ya había conseguido ser alcalde de Cáceres en 1905, a la vez que Juan Muñoz Chaves era diputado por el distrito y poco después, en 1909, director general de Administración Local en el Ministerio de la Gobernación, conseguía el acta de Alcántara en 1918. Cerrada la época constitucional con Primo de Rivera, siguieron aupados en el poder y Juan Muñoz Fernández de Soria fue otra vez alcalde de Cáceres en 1924. Por su parte, su hermano Fernando fue presidente de la Diputación de Cáceres entre 1919 y 1923. Representan, junto a los jefes de los partidos políticos turnistas en Cáceres, la actividad de uno de los grupos de amigos políticos que manejan la desmovilización de la provincia.

En la región extremeña, que intentaba despegarse del subdesarrollo ${ }^{25}$, los intereses de los hombres políticos estaban ligados a

${ }^{24}$ Oriundos de un pueblo de Badajoz, se establecieron en la capital de la Alta Extremadura al calor de la existencia de la Audiencia Territorial y llegaron a formar uno de los bufetes más renombrados de la ciudad.

${ }_{25}$ Algunos de estos diputados, hechura de los intereses oligárquicos y del sistema político que los garantizaba, no dudaron en formular en el Congreso frecuentes requisitorias a los poderes públicos, interesándolos, con arrebatada oratoria nutrida del tradicional discurso del "abandono», en la mejora de la precaria situación social extremeña. Fue, por ejemplo, el caso de la vibrante intervención de Rafael Durán Martín en 1906 pidiendo la ampliación de la red ferroviaria. 
grandes obras que requerían, para poner a punto una mejora de la infraestructura viaria, la ayuda del Estado. En este sentido la coincidencia, en los primeros años del siglo, del debate de los ferrocarriles secundarios y estratégicos, centrará la preocupación de los municipios y con ello abrirá grandes posibilidades a la actuación de las redes clientelares, de las que los diputados eran cabezas visibles. El marqués de Mirabel estuvo íntimamente relacionado con el anhelado y nunca construido ferrocarril de la Vera; el representante por Hoyos, Rafael Durán, con los ferrocarriles secundarios que pretendían unir Coria y Hoyos con Ciudad Rodrigo, o Muñoz y Fernández de Soria con el plan general de ferrocarriles secundarios entre Cañaveral y Ciudad Rodrigo.

Tal como había ocurrido en el siglo XIX, era la oligarquía agraria el colectivo básico que nutria a los grupos políticos monopolizadores de la representación popular. La oligarquía agraria extremeña era un grupo complejo, con grandes diferencias en sus niveles de riqueza o de extracción social y en constante renovación. Una de sus peculiaridades es la fuerte presencia de la aristocracia, que controlaba los primeros patrimonios, aunque con el paso del tiempo fueron enajenando parte de sus propiedades. Su poder territorial procedía en buena medida del pasado (régimen señorial, mayorazgos), aunque también la nobleza intervino activamente en el mercado de la tierra durante la pasada centuria. Por otra parte, no se puede olvidar la profunda renovación que conoció este colectivo a lo largo del XIX, bien a través de títulos viejos que adquirieron tierras en Extremadura (Marqués de la Romana, marqués de la Torrecilla, etcétera), bien gracias al ennoblecimiento de notables figuras de la burguesía de negocios, dueña de considerables patrimonios en la región (Antonio López y López). En definitiva, como telón de fondo de esta transformación hay que colocar a la Reforma Agraria Liberal.

Entre 1902 y 1923 continúa la tradición anterior. Así encontramos en la provincia de Cáceres a 13 aristócratas que representan a diferentes distritos, constituyendo un $43 \%$ de la representación provincial, manteniendo su presencia en seis de los siete distritos provinciales. El único distrito que no contó nunca con representación aristocrática fue el de Coria. En Badajoz la situación fue diferente. Únicamente cinco títulos ocuparon algunos de sus escaños. Cuatro de sus distritos no llegaron a conocer la representación nobiliaria; por el contrario, Almendralejo se convirtió prácticamente en feudo aristocrático, en las 11 elecciones habidas entre 1901 y 1923 en nueve ocasiones estuvo representado por nobles. Seguramente, de no haber tenido la posibilidad de integrarse en el Senado, más nobles hubiesen tenido que buscarse un escaño en el Congreso, compitiendo con los otros colectivos sociales. 


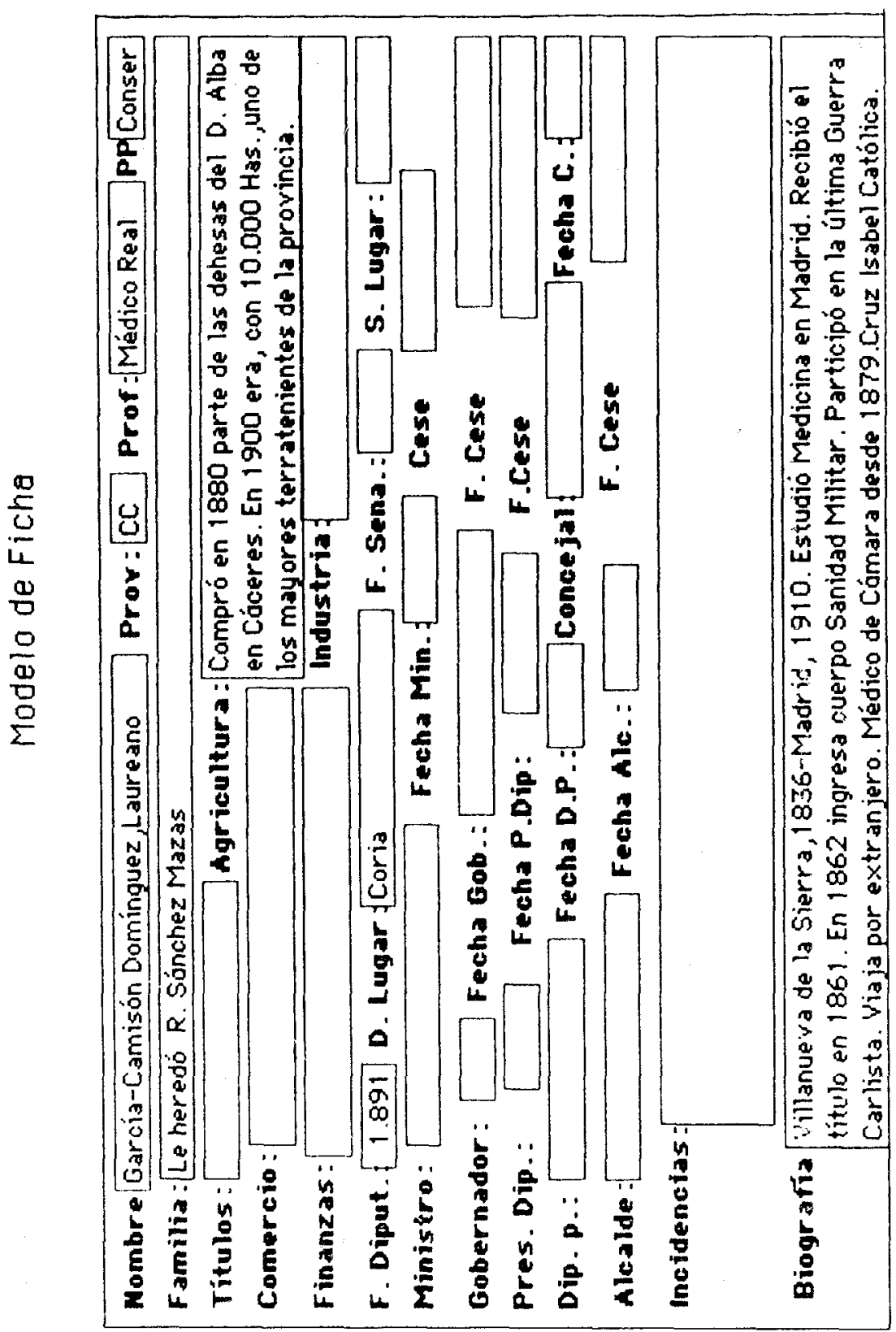


Junto a la aristocracia, compartía los primeros puestos de la oligarquía agraria la gran burguesía madrileña o autóctona, constituida por hombres de múltiples actividades económicas (banqueros, comerciantes, hombres de negocios en general) que aprovecharon las intensas transferencias de bienes típicas del siglo XIX para constituir su saneado patrimonio. Algunos apellidos como Cedrún, Garay, Muguiro, Sánchez de la Rosa, Albarrán, Sánchez-Arjona, Maeso, Gómez-Bravo, Fernández-Daza, etcétera, autóctonos y foráneos, representaban el grupo de los "nuevos señores de la tierra", muchos de ellos tradicionales participantes en política. El apellido Cedrún (Cedrún de la Pedraja y Gutiérrez Cedrún), tuvo importante peso en la vida política de Alcántara. También los hermanos Sánchez de la Rosa, Eloy y Andrés, abogados y grandes propietarios, participaron en la vida representativa, encontrando el primero apoyo en Navalmoral y el segundo en Cáceres gracias al protagonismo político de su padre Clemente Sánchez Ramos, banquero y terrateniente. En Plasencia desempeñaron un activo papel otros hermanos, los Delgado, protagonizando constantes abusos, bien mediante las comunes corrupciones, bien mediante la protección y cobertura municipales. Si todos ellos eran miembros de la oligarquía no aristocrática autóctona, la foránea encuentra en la figura de Antonio Garay Vitórica a un activo político, continuador de la tradición anterior del gran propietario venido de fuera, que monopolizaba la representación parlamentaria de la comarca donde se localizaba su ingente patrimonio rústico.

En suma, una parte de la oligarquía extremeña optó por la vocación política en el seno del modelo liberal, ocupando un escaño en el Parlamento representándose a sí misma, dado su alto nivel de riqueza. En el análisis de las élites políticas extremeñas se confirman las desigualdades en la representación política a favor de las clases dominantes por su situación económica o por su posición en el apartado constitucional. Así, los hombres que controlaban la vida económica de la región también monopolizaban la vida política y la social.

Por su parte, la clase obrera comenzó a pugnar, en proceso paralelo al de su propia maduración organizativa, para conseguir arrebatar los escaños de manos de las fuerzas tradicionales. Sin embargo, los distintos esfuerzos, tanto en Cáceres como en Badajoz, se saldaron con un fracaso y se mostró la incapacidad de las organizaciones obreras de romper el monopolio representativo, en lo que respecta al Parlamento, de los partidos políticos dinásticos, detentadores tradicionales de la representación. Habría que esperar a la Segunda República para que los partidos proletarios lograran entrar en las Cortes. 